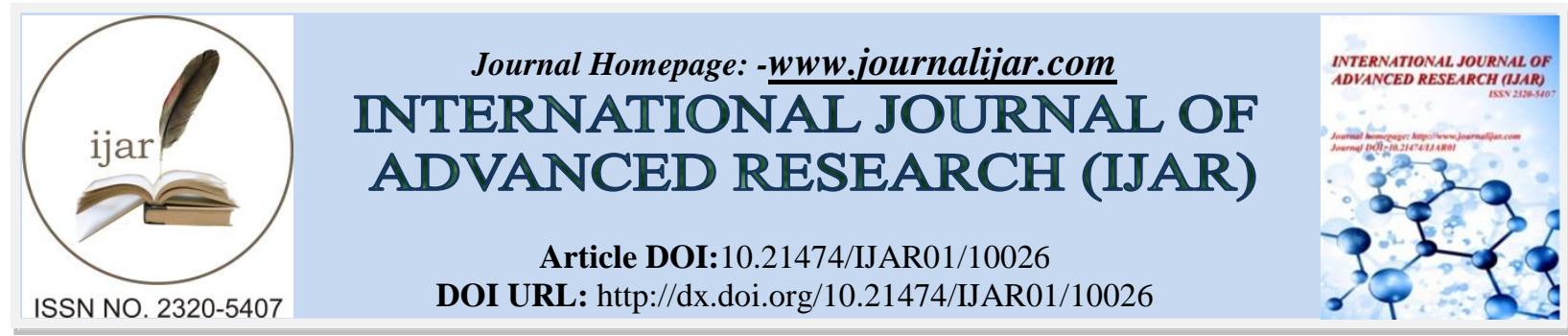

RESEARCH ARTICLE

\title{
CURRENT SITUATION OF SKILLS AND EMPLOYABILITY IN INDIA: ENGINEERING EDUCATION PERSPECTIVE.
}

1. PhD Scholar, PAHER University, Udaipur.

\section{Jagdeep Singh $^{1}$ and Mamta Kumari ${ }^{2}$.}

2. Assistant Professor, Junagadh Agricultural University, Amreli.

\section{Manuscript Info}

Manuscript History

Received: 10 September 2019

Final Accepted: 12 October 2019

Published: November 2019

Key words:-

Skills, Employability, Engineering Graduate, Curriculum, Education, Jobs, Career.

\begin{abstract}
The world becomes smaller place on earth and competition increases, everyone has to compete as no one has choice to complain. This is quite true in engineering education as well. Engineering is one of the oldest field exists on earth. It should be considered as the 'father' of human development as it exists in all fields whether it is engineering, medical, education, commerce, or any other fields etc. Being so much demanding field of study, it is not growing in a way as desired due to skills among the graduates, technological changes, and the scope of employability. Methodology used in this study is to collect secondary data and analyze it for conclusion \& recommendations. This study attempts to understand the current situation of skills and employability among the engineering graduates in India. After a rigorous review of literature, it is found that the majority of engineering passed graduates do not contain right, and required skills for the job they apply. It is also found that most of the candidates learn while they earn and grow as professional in the private or government jobs. This study proposed a framework of skills and employability to bridge the gaps and also proposed a career decision process for engineering graduates so that they could be able to choose right path! Right future career! This study concluded that educational Institutes and Industries should come together and make joint efforts to develop a curriculum so that it makes employable India and hence nations progressive growth.

This study may help engineering graduates, students who are willing to jump into engineering field, Government organizations related to engineering education, educationists and industries.
\end{abstract}

Copy Right, IJAR, 2019,. All rights reserved.

\section{Introduction:-}

Engineering is one of the oldest field exists on earth. It should be considered as the 'father' of human development as it exists in all fields whether it is engineering, medical, education, commerce, or any other fields etc. Engineering is used in all fields and hence we could say that its scope is extremely broad and diverse. Globalization and technology have twisted India into knowledge driven economy. Success of any nation is not only driven by the Technical knowledge, innovation, and participation by the people of the nation but also by the capabilities of the people, and higher education (especially engineering education). India has done phenomenally well in creating large infrastructure across the country to publicize engineering education in every State year after year. However we 
found the gap in terms of the skills and employability and hence we need to facilitate quality and accredited technical education at scale so that India could able to cater the next-generation of engineering skill requirements. (Reddy, 2018) The All India Council for Technical Education (AICTE) has been ably spearheading the planning, formulation, and dissemination of technical education across India. Over the years, it has undertaken several proactive steps for the growth of engineering education, maintenance of standards, and to keep the curricula current and relevant. (IndiaTodayWebDesk, 2017) Many policies have been changed and introduced new ones in past 3 years. Union Education Minister and all states are free to initiate more education policies. The Central Advisory Board of Education (CABE) is the highest advisory body to advise the Central and State Governments. AICTE does not allow arts and science courses in engineering institution as it does not approve these courses however if institute has additional infrastructure apart from fulfilling AICTE rules \& regulations, it may run other courses in same adjacent premise. Queries related to portal could be sent to: helpdesk1@aicte-india.org and Queries related to AICTE approval could be sent to:helpdeskab@aicte-india.org. National Apprenticeship Promotion Scheme (NAPS) is very important for developing future workforce. Haryana has mandated its departments to hire $10 \%$ of total workforce including contractual or outsourced manpower under NAPS scheme. Currently, only 230000 trade apprentices are undergoing apprenticeship training in 30 to 165 establishments across the country because of lack of awareness about new regulations. Indian government would increase the engagement of apprentices to 50 lakh cumulatively by 2020. Cities which have more employment prospects and employability are Bengaluru, Chennai, Indore, Lucknow, Mumbai, Nagpur, New Delhi, Pune, and Tiruchirappalli etc. There will be an impact of automation on job markets and employability as well. Graduates who will possess the right skills will be absorbed by the industry. The technologies such as robotics, artificial intelligence, and machine learning will be crucial for future and hence students need to be ready to take up the future challenges and groom themselves. (Mohanty $\&$ Dash, 2016) Engineering education in India faces significant challenges as it needs to meet the demands of technical profession and emerging job market. Presently, e-learners and online consumers are increasing year on year, for which it has to update digital world. Technical faculty must learn the innovative approaches to teaching and learning, which in turn will need effective professional development for both new and experienced instructors alike.

\section{Definition of Skills and employability \\ Skill:}

Skill is an ability and capacity acquired through deliberate, systematic, and sustained effort to smoothly and adaptively carryout complex activities or job functions involving ideas (cognitive skills), things (technical skills), and/or people (interpersonal skills).

\section{Employability: ‘}

Ability to gain initial employment, maintains employment, and obtains new employment if required. In simple terms, employability is about being capable of getting and keeping fulfilling work. "Employability is having a set of skills, knowledge, understanding and personal attributes.'

\section{Education and employability}

The term 'employability' indicates that an individual possesses abilities, skills, and attributes to get a employment, and to be successful in his/her profession, which will lead to overall progress of the nation. Employee must deliver what is expected from him/her by the industry. Although, education and employability are two separate things, but it has been assumed since long that possessing a higher degree will offer a guarantee of getting a handsome employment. Everyone expects that higher education institutes must function in such a way to develop employability among the students in respective fields of study.

\section{Role of Higher Education, particularly engineering education in India}

Higher education plays an important role in nation building. In higher education, specially, technical (engineering) education is accountable for preparing the next generation of government executives, business leaders, and educators. Engineering education plays a fundamental role in knowledge driven societies.

\section{Who can enroll in engineering education?}

Normally, A student who has PCM (Physics, Chemistry and Mathematics) in his/her $12^{\text {th }}(10+2)$ may enroll in engineering programme (BE/B.Tech) in a college/University. There may be percentage criteria to get into engineering. General percentage in $10+2$ should be at least $50 \%$ marks however it varies based on category and individual university/college rules. Percentage $(10+2)$ eligible criteria for Indian Institute of Technology (IIT) are 
$60 \%$. There are many modes of admission like direct admission, admission based on $10+2$ percentage merit, or admission through entrance exam. There are various entrance exams such as IIT-JEE, AIEEE etc.

\section{Current Engineering Education System in India}

(The Institution of Engineers, Australia) The main branches of engineering are electrical, mechanical, electronics, chemical, and civil. Engineering field is so much vast as so many branches are there however few of them have been quoted as below:

1. Computer Science and Engineering.

2. Computer systems engineering

3. Software engineering

4. Electronics engineering

5. Electronics and Instrumentation Engineering.

6. Instrumentation and Electronics Engineering.

7. Electronics and Electrical Engineering.

8. Electronics and Telecommunication Engineering.

9. Electronics and Communication Engineering.

10. Mechanical Engineering.

11. Production/Manufacturing Engineering

12. Automobile Engineering

13. Paint Technology/Paint Engineering

14. Electrical Engineering.

15. Civil Engineering.

16. Chemical Engineering.

17. Biochemical / Biomedical Engineering.

18. Aerospace / Aeronautical Engineering

19. Agricultural Engineering

20. Biomedical Engineering

21. Chemical Engineering

22. Electrical Engineering

23. Environmental Engineering

24. Materials Engineering

25. Metallurgical or Minerals Engineering

26. Food Technology

27. Mining engineering

28. Resource engineering

29. Structural engineering

30. Telecommunications engineering

31. Petroleum Engineering

\section{Study Methodology:-}

The objective of the study was to understand the gaps in skills \& employability of engineering graduates in India and hence data collection and analysis was done and found multiple gaps. Results reviewed and the recommendations were put forward for improvements through the educationalists, Government and Industries. Finally, the research was concluded. Bullet Points of the methodology are given below:

1. Data Collection and Analysis

2. Gap Analysis and Recommendations

3. Conclusion

\section{Data collection and Analysis:-}

Data collection is done through the secondary sources such as AICTE website, various reports, and other authentic websites. Most of the data used is from AICTE website. Data analysis found many trends as per graphs from 1 to 5. Major trends are placements are decreasing, enrolments are decreasing, and institutes are shutting down. 
Table 1:-Data (Year 2018-19) of Engineering and Technology Area

\begin{tabular}{|l|l|l|l|l|l|}
\hline Engineering and Technology & UG & PG & Diploma & Total addition of UG,PG, and Diploma & $\begin{array}{l}\text { Total as Per } \\
\text { AICTE } \\
\text { Website }\end{array}$ \\
\hline Total Institutions & & & & & 6276 \\
\hline New Institutions & 8124 & 2067 & 3779 & 8970 & 154 \\
\hline Closed Institutions & 11 & 64 & 60 & 208 & 24 \\
\hline Total Intake & 1404820 & 182228 & 1124974 & 2712022 & 2712022 \\
\hline Girl's Enrolment & 210098 & 25855 & 102915 & 338868 & 338868 \\
\hline Boy's Enrolment & 505454 & 40258 & 515082 & 1060794 & 1060794 \\
\hline Faculty (Teachers) & 338193 & 25551 & 119961 & 483705 & 483705 \\
\hline \#Students Passed* & 0 & 0 & 0 & 0 & 0 \\
\hline Placement & 383792 & 17043 & 197981 & 598816 & 598816 \\
\hline * Data not available & & & & \\
\hline
\end{tabular}

Table 2:-Data (Year 2012-13) of Engineering and Technology Area

\begin{tabular}{|l|l|l|l|l|l|}
\hline Engineering and Technology & UG & PG & Diploma & Total addition of UG,PG, and Diploma & $\begin{array}{l}\text { Total as Per } \\
\text { AICTE } \\
\text { Wear 2012-13 }\end{array}$ \\
& & & & & 6099 \\
\hline Total Institutions & 3371 & 1910 & 3060 & 8341 & 223 \\
\hline New Institutions & 114 & 18 & 103 & 235 & 9 \\
\hline Closed Institutions & 9 & 0 & 0 & 9 & 2699617 \\
\hline Total Intake & 1552084 & 138366 & 1009167 & 2699617 & 563042 \\
\hline Girl's Enrolment & 320795 & 42601 & 199646 & 563042 & 1190299 \\
\hline Boy's Enrolment & 647034 & 58982 & 484283 & 1190299 & 306978 \\
\hline Faculty (Teachers) & 215385 & 34140 & 57453 & 306978 & 1073846 \\
\hline \#Students Passed & 658029 & 52763 & 363054 & 1073846 & 412845 \\
\hline Placement & 273638 & 13094 & 126113 & 412845 & \\
\hline
\end{tabular}

Table 3:-Data (Year 2013-14) of Engineering and Technology Area

\begin{tabular}{|l|l|l|l|l|l|}
\hline Engineering and Technology & PG & Diploma & Total addition of UG,PG, and Diploma & $\begin{array}{l}\text { Total as Per } \\
\text { AICTE } \\
\text { Website }\end{array}$ \\
\hline Total Institutions & 3383 & 2157 & 3436 & 8976 & 6218 \\
\hline New Institutions & 51 & 3 & 73 & 127 & 126 \\
\hline Closed Institutions & 16 & 3 & 6 & 25 & 21 \\
\hline Total Intake & 1634298 & 181563 & 1135989 & 2951850 & 2951850 \\
\hline Girl's Enrolment & 260050 & 51979 & 113142 & 425171 & 425171 \\
\hline Boy's Enrolment & 684340 & 74770 & 615850 & 1374960 & 1374960 \\
\hline Faculty (Teachers) & 301841 & 45110 & 78843 & 425794 & 425794 \\
\hline \#Students Passed & 712700 & 70096 & 407521 & 1190317 & 1190317 \\
\hline Placement & 295567 & 17150 & 142868 & 455585 & 455585 \\
\hline
\end{tabular}

Table 4:-Data (Year 2014-15) of Engineering and Technology Area

\begin{tabular}{|c|c|c|c|c|c|}
\hline \multicolumn{6}{|c|}{ Engineering and Technology } \\
\hline Year 2014-15 & $\mathbf{U G}$ & PG & Diploma & Total addition of UG,PG, and Diploma & $\begin{array}{l}\text { Total as Per } \\
\text { AICTE } \\
\text { Website }\end{array}$ \\
\hline Total Institutions & 3400 & 2338 & 3799 & 9537 & 6385 \\
\hline New Institutions & 46 & 3 & 103 & 152 & 152 \\
\hline Closed Institutions & 15 & 5 & 5 & 25 & 18 \\
\hline
\end{tabular}




\begin{tabular}{|l|l|l|l|l|l|}
\hline Total Intake & 1705437 & 215550 & 1261788 & 3182775 & 3182775 \\
\hline Girl's Enrolment & 240177 & 50014 & 112278 & 402469 & 402469 \\
\hline Boy's Enrolment & 635057 & 72648 & 629332 & 1337037 & 1337037 \\
\hline Faculty (Teachers) & 389711 & 54213 & 114007 & 557931 & 557931 \\
\hline \#Students Passed & 760413 & 84071 & 424648 & 1269132 & 1269132 \\
\hline Placement & 335404 & 22935 & 155335 & 513674 & 513674 \\
\hline
\end{tabular}

Table 5:-Data (Year 2015-16) of Engineering and Technology Area

\begin{tabular}{|l|l|l|l|l|l|}
\hline Engineering and Technology & & & & Total addition of UG,PG, and Diploma & $\begin{array}{l}\text { Total as Per } \\
\text { AICTE } \\
\text { Website }\end{array}$ \\
\hline Year 2015-16 & UG & PG & Diploma & 6431 \\
\hline Total Institutions & 3363 & 2306 & 3852 & 9521 & 89 \\
\hline New Institutions & 35 & 6 & 49 & 90 & 52 \\
\hline Closed Institutions & 39 & 17 & 20 & 76 & 3094596 \\
\hline Total Intake & 1631030 & 207397 & 1256169 & 3094596 & 392606 \\
\hline Girl's Enrolment & 238308 & 37167 & 117131 & 392606 & 1286006 \\
\hline Boy's Enrolment & 616585 & 53132 & 616289 & 1286006 & 578206 \\
\hline Faculty (Teachers) & 403786 & 53509 & 120911 & 578206 & 1325436 \\
\hline \#Students Passed & 787316 & 86423 & 451697 & 1325436 & 546692 \\
\hline Placement & 361868 & 22874 & 161950 & 546692 & \\
\hline
\end{tabular}

Table 6:-Data (Year 2016-17) of Engineering and Technology Area

\begin{tabular}{|l|l|l|l|l|l|}
\hline Engineering and Technology & & & & \\
\hline Year 2016-17 & UG & PG & Diploma & Total addition of UG,PG, and Diploma & $\begin{array}{l}\text { Total as Per } \\
\text { AICTE } \\
\text { Website }\end{array}$ \\
\hline Total Institutions & 3293 & 2236 & 3925 & 9454 & 6474 \\
\hline New Institutions & 30 & 2 & 145 & 177 & 176 \\
\hline Closed Institutions & 52 & 21 & 29 & 102 & 67 \\
\hline Total Intake & 1557110 & 197166 & 1244862 & 2999138 & 2999138 \\
\hline Girl's Enrolment & 228015 & 27607 & 114365 & 369987 & 369987 \\
\hline Boy's Enrolment & 557539 & 41792 & 591295 & 1190626 & 1190626 \\
\hline Faculty (Teachers) & 406980 & 47426 & 121216 & 575622 & 575622 \\
\hline \#Students Passed & 797798 & 70477 & 532447 & 1400722 & 1400722 \\
\hline Placement & 363777 & 19295 & 178393 & 561465 & 561465 \\
\hline
\end{tabular}

Table 7:-Data (Year 2017-18) of Engineering and Technology Area

\begin{tabular}{|l|l|l|l|l|l|}
\hline Engineering and Technology & \multicolumn{5}{|l|}{} \\
\hline Year 2017-18 & UG & PG & Diploma & Total addition of UG,PG, and Diploma & $\begin{array}{l}\text { Total as Per } \\
\text { AICTE Website }\end{array}$ \\
\hline Total Institutions & 3225 & 2138 & 3918 & 9281 & 6446 \\
\hline New Institutions & 32 & 4 & 104 & 140 & 143 \\
\hline Closed Institutions & 41 & 20 & 31 & 92 & 59 \\
\hline Total Intake & 1476428 & 186042 & 1208518 & 2870988 & 2870988 \\
\hline Girl's Enrolment & 219772 & 26847 & 109877 & 356496 & 356496 \\
\hline Boy's Enrolment & 530548 & 41828 & 557854 & 1130230 & 1130230 \\
\hline Faculty (Teachers) & 406927 & 40860 & 133914 & 581701 & 581701 \\
\hline \#Students Passed & 737549 & 55421 & 441980 & 1234950 & 1234950 \\
\hline Placement & 343301 & 15722 & 194129 & 553152 & 553152 \\
\hline
\end{tabular}


Graph 1:-Trend Analysis Chart Yearwise of Under Graduate Engineering Students

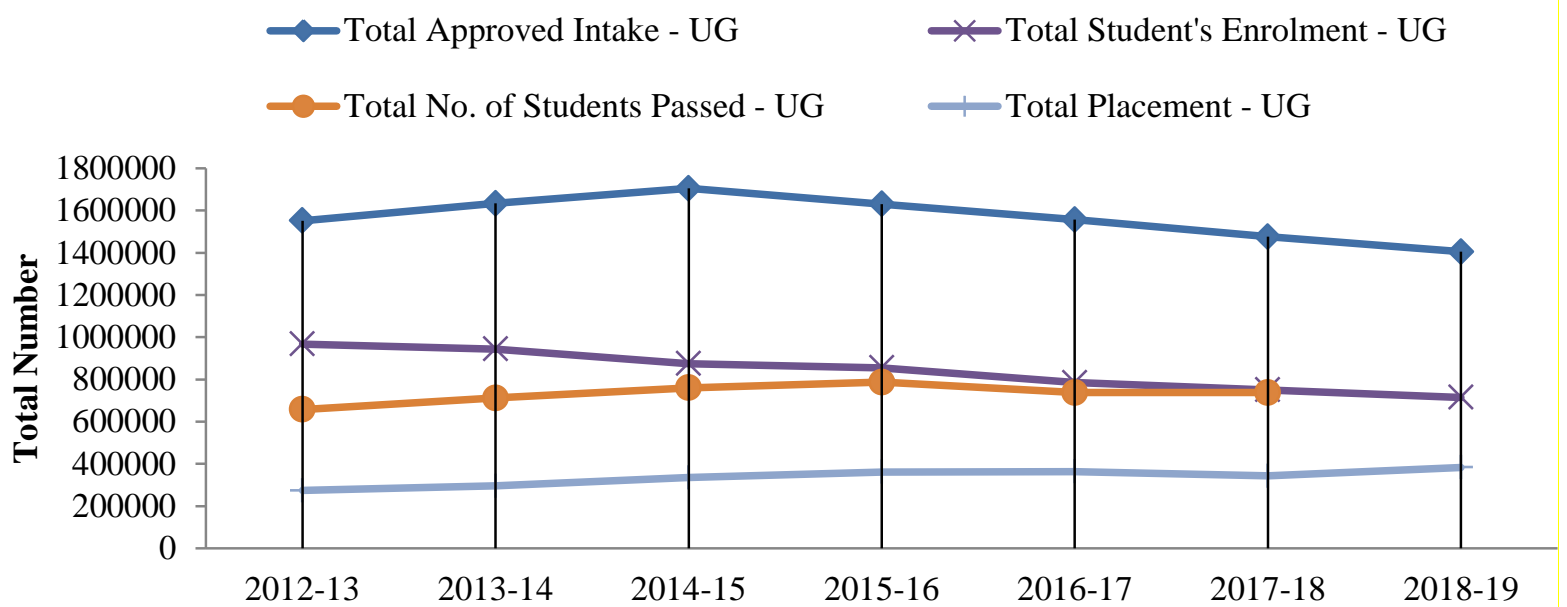

Graph 2:-Bar Chart of Under Graduate Engineering Student's Enrolments Genderwise

घ Girl's Enrolment $\quad \square$ Boy's Enrolment $\quad \square$ Total Enrolment

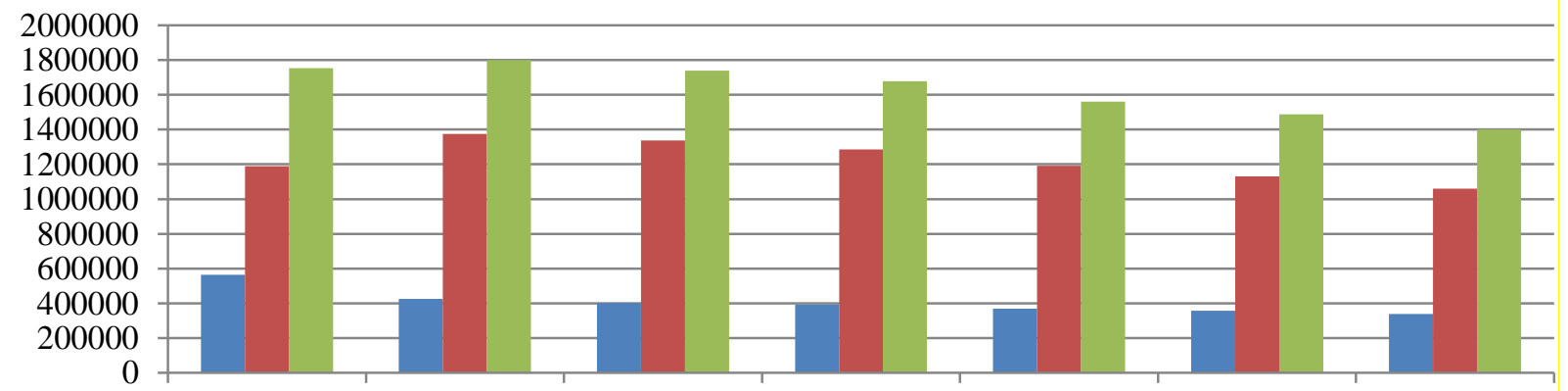

Year 2012-13 Year 2013-14 Year 2014-15 Year 2015-16 Year 2016-17 Year 2017-18 Year 2018-19

Graph 3:- Trend Chart of Opening and closing of engineering institutes in India

Total Engineering Related Institutions Trends Year Wise

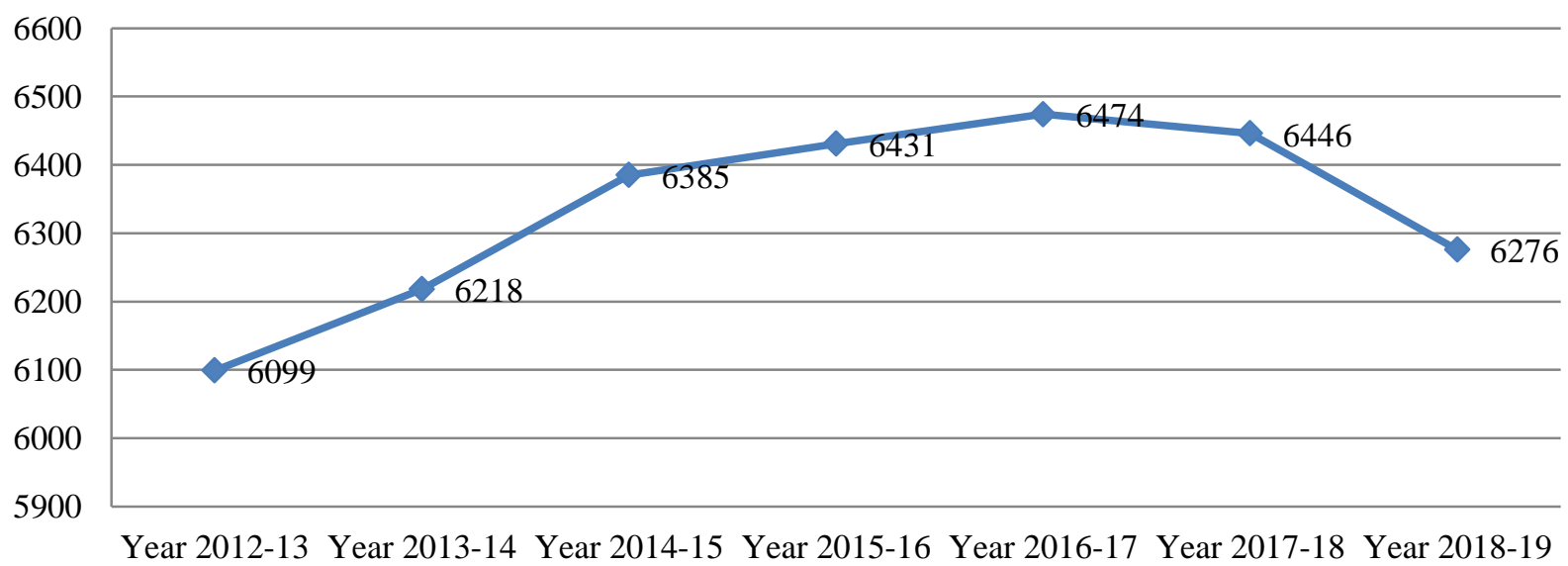


Graph 4:-Bar Chart of Under Graduate Engineering Student's Enrolments Genderwise

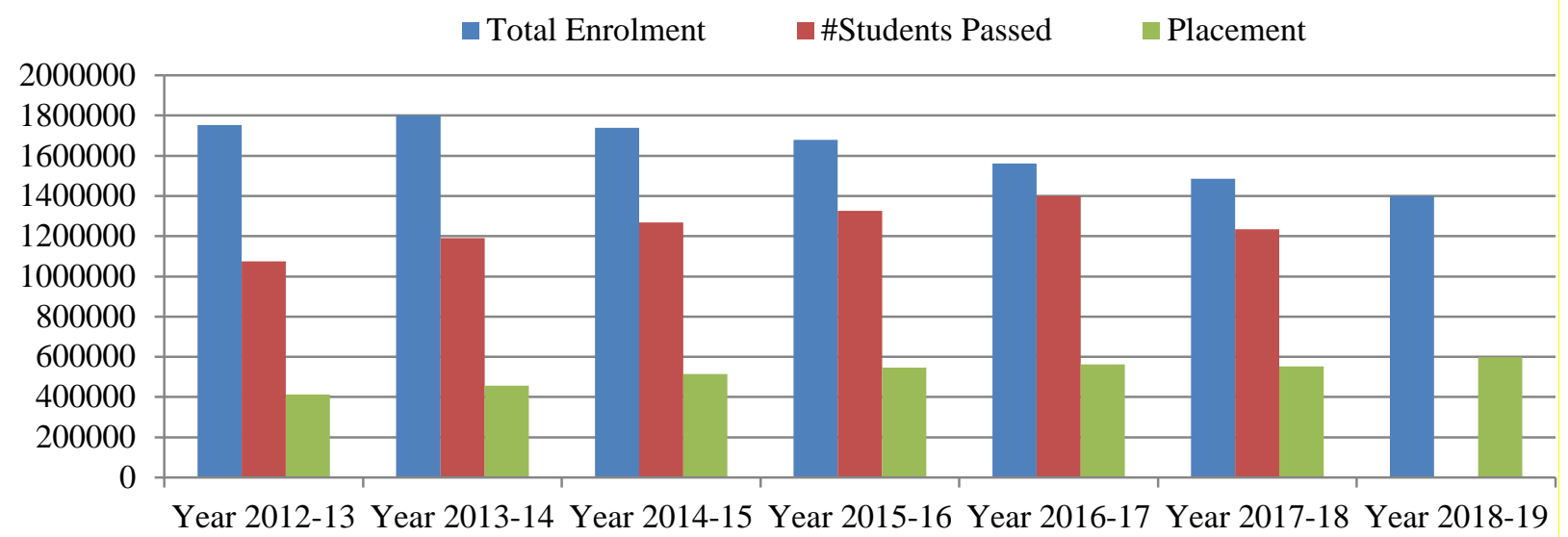

Graph 5:- Comparision of Placement Trends and Employability Trends

$\checkmark$ Placement trends of Engineering \& Technology field of study (UG, PG \& Diploma) as per AICTE Data (2013-14 session's placements assumed as 2014 and so on)

-Employability Trends as per India Skills Report-2018 (It does not include IITs, IIMs and NITs)

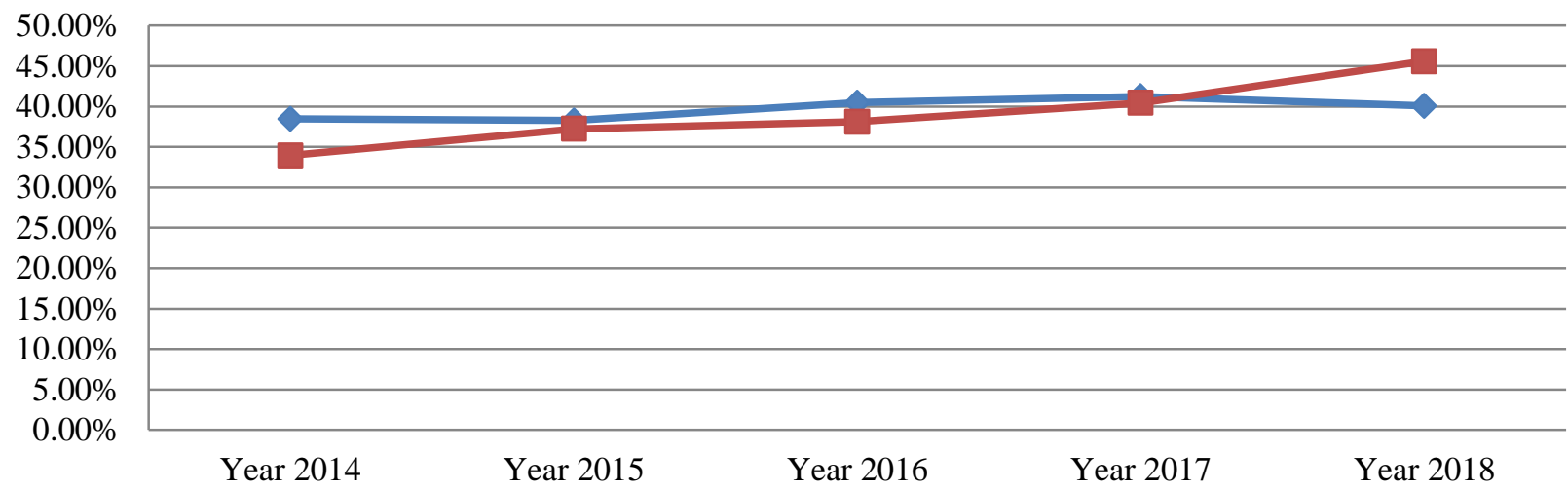

\section{Gap Analysis:-}

There were issues in employability in India. As per India Skills Report 2018 published through UNDP, says that there is a huge problem in employability which is not limited to traditional \& non technical courses but also to the engineering domain (India Skills Report 2018: Future Skills, Future Jobs, 2018). There are multiple other reports which explained various gaps. This study distributed the gaps in 3 different (A, B, and C) categories as below:

\section{A. Gaps for Engineering Graduates}

1. Right and Required Skills among the Students (Refer - Figure-2)

2. Lacking in Right Approach (Refer - Figure-1)

3. Employability Gap: No Employment

\section{B. Gaps for Trainers}

Trainers Unavailability as Per Requirement: Scaricity of skills among the trainers

\section{Gaps for Educationalists, Government and Industries}

1. Lack of Integration among Educationalists, Government and Industries: Integrated approach is required to develop a curriculum / course

2. Lack of Jobs: Jobs to be created

3. It was found that future skills required are Artificial Intelligence (AI) \& Robotics are leading the next gen jobs along with others. It also takes a stock of skills availability and aspirations from candidate. The survey clearly 
highlights that nearly $50 \%$ of the applicants appearing for the interview either do not meet the skills requirement or some may possess the required skills to meet the basic requirement of employers.

\section{Is our education system $\mathrm{OK}$ and do educational institutes having capable trainers?}

This question is very much valid and every engineering student should ask to their respective institutes. There are huge gaps of required skills among the trainers which create gaps and contribute in producing unskilled engineering graduates. Trainer must be equipped with all skills, experience, knowledge and more over lecture delivery skills required to polish to the student's for better tomorrow. Every individual institute must follow AICTE norms and must have skilled trainers so that they could transfer their knowledge and experiences to the respective students for making students employable and hence these individuals could help in nation building \& progress.

\section{How do the students decide their career in India? Is it right Approach? If not, what is the right Approach?}

The entry into engineering requires certain basic traits. First and foremost, candidate must be passionate about engineering and he/she should choose the respective choice of branch in engineering field so that he/she could give their $100 \%$ and make it interested throughout the course. Someone who is not interested in engineering/technology field of study however he/she choose this field of study due to peer pressure, family pressure or under any other circumstances, it will not be good for individual as well as nation. Hence, individual should have freedom to choose their choice of field of study so that it could give its $100 \%$ efforts with interest and passion. If someone is interested in commerce, he/she should study commerce, if someone is interested in acting, he/she should go for that and so on. If someone is interested in engineering, he/she study engineering. Individual must have enormous patience, ability to work for long hours and an creative spirit that are essential ingredients for becoming a successful engineer. This study is proposing here two processes as below:

A. A basic 'seven steps' approach to decide individual's field of study

B. 'Career Decision Process' for Engineering Graduates

\section{A. A basic 'seven steps' approach is as below:}

1. Do a research and explore the opportunities available

2. Self assessment to be done

3. Choose the area of passion (interest) - "Goal Setting"

4. Start working 'honestly' towards achieving your goal

5. Periodic monitoring and assessment whether you are on track

6. Be flexible

7. Achieve the goal and Cheers!!

\section{B. 'Career Decision Process' for Engineering Graduates}

In the Figure-1, career decision process for engineering graduates is explained. It is simple to understand. 


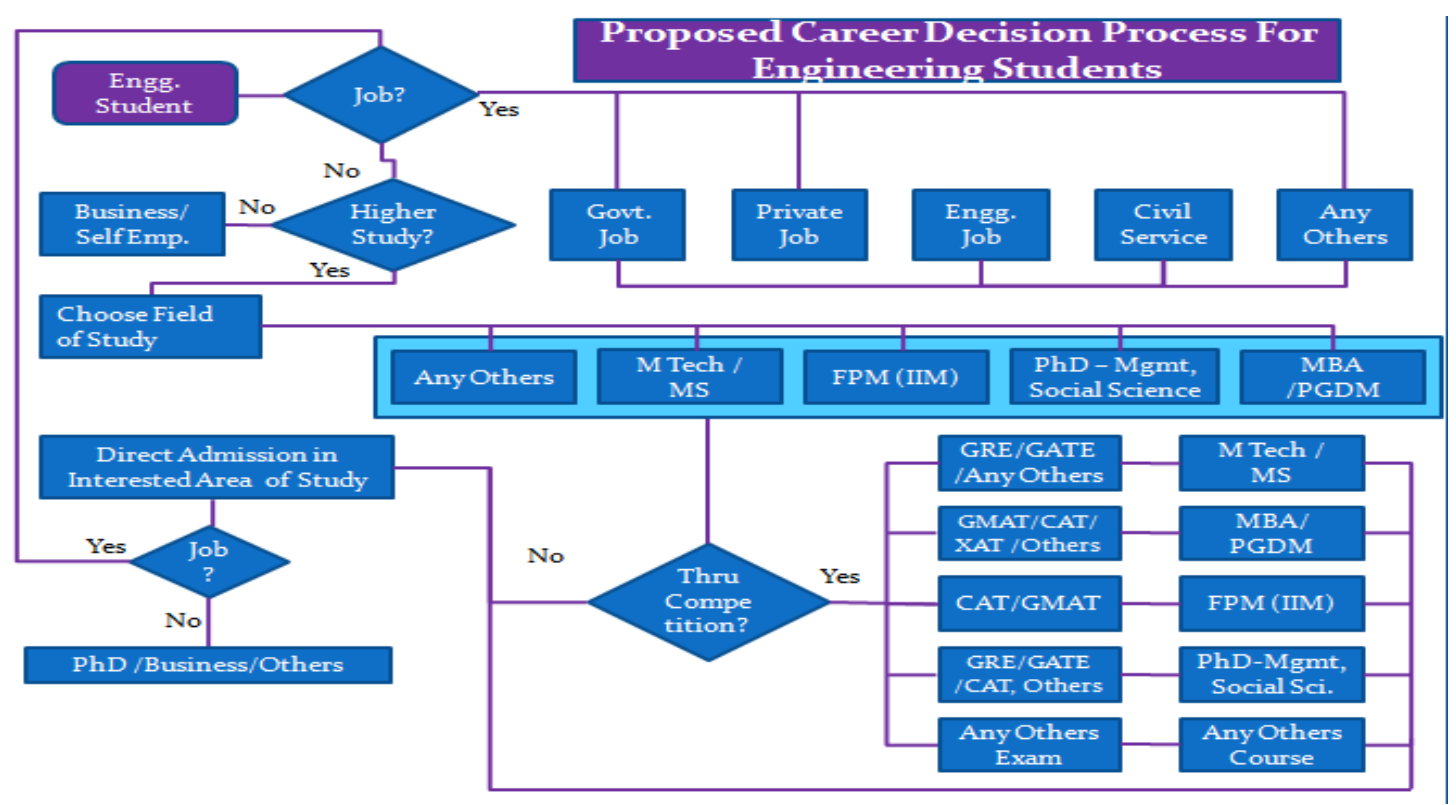

Figure 1:- Career Decision Process for Engineering Graduates

\section{Proposed Framework of Skills and Employability for Engineering Graduates}

After reviewing many books and journals, it was felt a need of a framework for engineering graduates. Hence, the study proposed a framework as shown in Figure-2. It states that engineering graduates must possess basic (Analytical, Problem solving and creative skills), technical (Technical, Planning and Decision Making Skills) and social (Communication and People Skills) skills along with positive attitude to become successful professional.

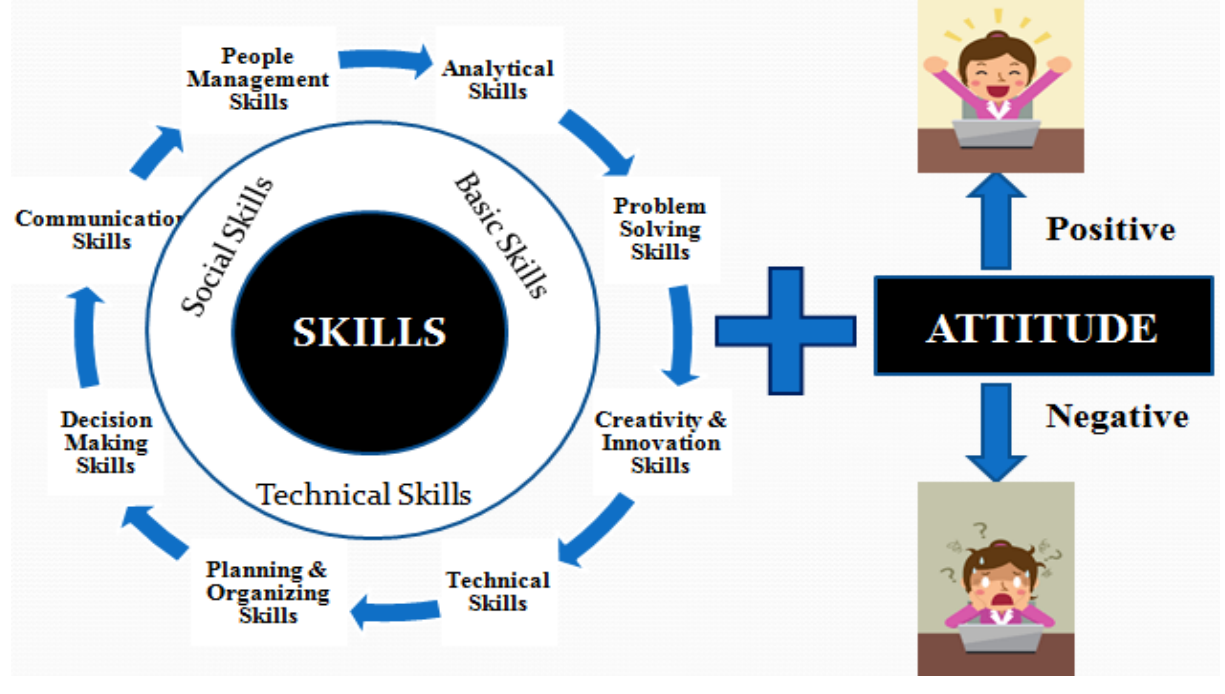

Figure 2:-Proposed Framework of Skills and Employability for Engineering Graduates

\section{Key Facts from Survey Findings:}

1. Employability score has touched a new high of $45.60 \%$.

2. Hiring intent for Year 2018 is positive with an increase of $10-15 \%$ as compared to last year.

3. $69 \%$ of India Hiring Intent Survey respondents agree to the impact of automation on jobs in future.

4. $24 \%$ employers indicate that analytics is emerging as the future job area and $15 \%$ foresee Artificial intelligence as future job area

5. $8.11 \%$ employers suggest that very few job seekers possess the required skill while $9.01 \%$ employers agree that nearly all job seekers possess the required skill. 
6. $64 \%$ employers are aware of Apprenticeship Scheme, out of which 56\% have registered under NAPS.

AICTE put efforts to support the reforms in engineering education and It is studied the current state of engineering education and put a short and medium term plan and recommendations (Reddy, 2018).

1. Traditional engineering disciplines such as Mechanical, Electrical, Civil and Electronics engineering capacity utilization around $40 \%$ as opposed to Computer Science and Engineering, Aerospace Engineering, Mechatronics being in the high $60 \%$. This is clear pointer that the demand lies in emerging technologies as opposed and hence no additional seats are approved.

2. The poor employability of engineering graduates is reflecting poorly on the faculty - shortage and quality, and pedagogy. It may be very important to take immediate steps to improve the quality of our teachers.

3. The low enrollment, lower placements, and low employability are causes for concern. Employment generation is very critical to a nation's economic development.

4. As research becomes democratized, funds would need to be spent most optimally. Institutions need to build project management capabilities around research to ensure quick turnarounds, reduce cost and schedule overruns, and better collaborations across industry and academia.

5. Academic institutions have to continuously monitor the future skill requirementsand make suitable changes to content and pedagogy so that the graduating studentshave the right capabilities for the job-in-demand. Hence, an institutionalmechanism for periodic industry feedback on the technology up-gradation and itsimpact on job roles needs to be put in place.

6. There is evidence to point out that the current industry-academia interaction requires improvement. We recommend the following interventions:

1. Analytical tools should be used to understand the impact of various teaching methods and identify the best methods of executing coursework and apprenticeship - tightly integrate apprenticeship with pedagogy.

2. Apprenticeship should be made mandatory on industry (in some ways it exists but needs rigorous implementation) and also progressively mandatory on educational institutions (starting with $25 \%$ moving to $100 \%$ in five years.

3. Two industry representatives to be part of the advisory board of each institution.

4. Deepening of industry-academia partnerships in applied research needs to be encouraged.

5. Establish 20 National Knowledge Functional Hubs (NKFH) as a pilot in AICTE approved institutions to create an ecosystem of sustained industry-academia engagement.

6. We recommend that AICTE takes the local industry ecosystem requirements (For instance, aerospace \& IT engineering in Bangalore vicinity, automotive in Chennai and Pune) in to consideration while creating new capacities or increasing the existing capacities to deepen domain knowledge and to meet the industry requirements.

7. Simultaneously, we recommend that AICTE balances this step with the national and global needs by introducing courses in new and disrupting technologies which are fungible across the country.

We have evidence to show that innovation, incubation and start-up ecosystem is lacking in educational institutions. As has been rightly recognized by GOI, start-ups are a key driver for employment generation and wealth creation. Every education institution should be mandated for the following:

1. Entrepreneurship should be a minor elective for undergraduates.

2. Tinkering labs similar to Atal Innovation Labs to be setup in every educationalinstitution.

3. To promote start-ups, educational institutions need to setup incubation centers, mentoring clubs, and accelerator programs.

Proxy indicators such as venture capital investments and engineering $R \& D$ investments by large companies for forecasting future technology shows a clear trend towards software and internet industries, healthcare services, and medical devices and semiconductor industry. They also clearly indicate that artificial intelligence (AI), internet of things (IoT) embedded SW, internet SW, mobility, analytics, and cloud are growing at a rapid pace as compared to traditional technologies. The results of the NASSCOM - BCG study and FICCI-NASSCOM-EY study also concur with this analysis.

1. Across all engineering disciplines, we recommend that courses in these emerging technologies are made part of the curricula and made mandatory for computer science, electrical, and electronics engineering.

2. Specifically, we recommend introducing undergraduate engineering programs exclusively focused in AI, IoT, Blockchain, Robotics, Quantum Computing, Data Sciences, Cyber Security, 3D Printing \& Design, AR/VR (Indicative list). 
3. Also, we recommend that we put greater focus on multi-disciplinary engineering courses, especially in computational biology, biotechnology, biomedical, mechatronics, space, aerospace, agriculture, and environmental engineering, by reducing the seats in conventional disciplines and converting some of the existing seats into these areas.

Research on future trends in education indicates student-centric learning needs to be given precedence.

1. We recommend students should be encouraged on design thinking and practical approaches to learning.

2. Students should also be made aware of real life socioeconomic problems for them to solve using technology learning.

3. Technology should be used for individual learning paths for each student (Education 4.0).

4. MHRD/AICTE should make investments in innovation in education and incubate education start-ups.

5. Open book examinations should be introduced wherever applicable to move tudents to higher order cognitive skills.

Finally, developing a perspective plan for engineering education should be an ongoing exercise. In the backdrop of rapidly-changing technology environment, engineering education needs continuous monitoring. We recommend that one of the industry bodies or a smaller group of industry bodies with the help of consultants who have a focus on education be tasked with this periodic planning exercise once every two years.

\section{Challenges}

1. Teacher's training and methods \& principles of teaching

2. Level of Interest of the students

3. Revision frequency of course curriculum

4. Infrastructure to gain practical knowledge

5. New technologies - Internet of Things (IoT), Cloud Computing, Digital Marketing, Data Science, Big Data Analytics, Robotics etc.

\section{Employability Challenges for Engineering Graduates}

1. Academia curriculum is mostly not in line with the skill requirements of industries

2. Teacher's regular trainings are not happening in line with the required skills

3. Lack of passion (interest) among the students in respective studies

4. Course curriculum is not in line with the respective Industries

5. Lack of infrastructure to gain practical knowledge at education (UG/PG) level

6. Lack of communication skills

7. Evolution of new technologies - New technologies could be advance Robotics, Artificial Intelligence (AI) / Machine Learning, Internet of Things (IoT), Cloud Computing, Data Science, Big Data Analytics etc., It is estimated that almost 50 percent of activities could be automated by adapting currently demonstrated technologies.

Evolution of disruptive technologies of Industries 4.0 is coinciding with the rapid emergence of environmental constraints as it may create inequality among the peers. This development is bringing in a new era of globalization.

\section{What is Industry looking for?}

In the current scenario, employers look at academics not only as achievements, but also for three key types of skills: cognitive, non-cognitive, and technical skills. Cognitive skills include critical thinking and basic functions like literacy and numeracy. Non-cognitive skills Or behavioral skills include interpersonal communication skills, while technical skills are usually geared towards a specific occupation. While technical and basic cognitive skills are still important in workplaces, transferrable and non-cognitive skills such as communication, problem-solving, punctuality, and flexibility are increasingly important, particularly for the informal economy. Crucial non-cognitive skills are not being acquired by students in the present academic setting. Although the curriculum is getting reviewed to better promote skills such as teamwork and communication, actual teaching and learning have not kept pace. Teachers are often not appropriately trained to impart these new skills, and still take a "direct transmission" view of teaching, where rote-learning is common and teaching is geared only towards the national examinations, which are themselves mainly geared towards selection for further admissions. 


\section{Recommendations to Minimize the Employment Challenges for Engineering Graduates:-}

1. Academia curriculum to be revised and should be in line with the respective industries

2. Teacher's regular trainings should happen on required skills

3. Minimum eligibility should be $\mathrm{PhD}$ to teach in higher education (UG/PG)

4. Innovative ways to be adapted to enhance the level of Interest among the students

5. Labs \& other infrastructure to be in-line with course to ensure practical experience

6. University/Institute to facilitate to enhance knowledge as well as hand on experience (If possible) on upcoming \& new technologies like Advance Robotics, Artificial Intelligence (AI), Machine Learning, IoT, Cloud Computing, Data Science, Big Data Analytics

\section{Area of Scope for Engineering Graduates}

The requirement of engineering graduates is almost in every field and hence we could not point out few industries or companies. In each industry and company, engineering graduates are preferred and recruited. The scope is very vast and it will be injustice towards it to bind it in a limited or a particular scope.

\section{Conclusion:-}

There is an urgent need to address the problems inadequately the technical education; otherwise India will miss the opportunity to utilize its demographic surplus of a young work force which it has. In order to ensure the global standards and norms, there should be some mechanism to monitor with unbending attitude. In this admiration, Education in India needs to be more skill oriented - both in terms of life-skills as well as livelihood skills. There should also an immediate requirement of creating jobs for engineering graduates so that the gap in employability to be reduced and students to attract again towards engineering $\&$ technology to cater future needs.

\section{Bibliography:-}

1. (n.d.). Retrieved September 10, 2019, from The Institution of Engineers, Australia: https://www.me.ua.edu/ges100/Explore/study-branch.htm

2. (2018). India Skills Report 2018: Future Skills, Future Jobs. UNDP.

3. IndiaTodayWebDesk. (2017, January 6). https://www.indiatoday.in/education-today. Retrieved September 10, 2019, from https://www.indiatoday.in/education-today/featurephilia/story/education-policy-2016-953001-201701-03

4. Mohanty, A., \& Dash, D. (2016). Engineering Education in India: Preparation of Professional Engineering Educators. Journal of Human Resource and Sustainability Studies, 4, 92-101.

5. Reddy, B. M. (2018). Engineering Education in India - Short \& Medium Term Perspectives. New Delhi: AICTE.

6. All India Council for Technical Education. URL - https://www.facilities.aicteindia.org/dashboard/pages/dashboardaicte.php, Data downloaded on August 10, 2019. 